NBER WORKING PAPER SERIES

SELF-EMPLOYMENT AND LABOR FORCE

PARTICIPATION OF OLDER MALES

Victor R. Fuchs

Working Paper No. 584R

\author{
NATIONAL BUREAU OF ECONOMIC RESEARCH \\ 1050 Massachusetts Avenue \\ Cambridge, MA 02138
}

November 1980

Revised April 1981

This research was begun with financial support from
The Russell Sage Foundation and completed with fund-
ing from The Andrew W. Mellon Foundation. Phillip
Farrell did an excellent job of transforming the
original survey tapes into a useable data file, and
provided valuable research assistance. The partici-
pants in the Stanford University Labor Workshop
offered many helpful suggestions, and I am also
grateful to Alan Blinder, Edward Lazear, Arnold Zellner,
and two anonymous reviewers for helpful comments.
Any opinions expressed are those of the author and not
those of the National Bureau of Economic Research.
The research reported here is part of the NBER's
research program in Labor Studies. 


\title{
SELF-EMPLOYMENT AND LABOR FORCE
}

PARTICIPATION OF OLDER MALES

\begin{abstract}
This longitudinal analysis of the labor market behavior of older, urban white males in 1969,1971 , and 1973 focuses on changes from wageand-salary to self-employment and changes from working to non-working status. In each two-year transition approximately four percent of wageand-salary workers switched to self-employment. They were primarily men who were previously self-employed or who were in wage-and-salary occupations with characteristics similar to self-employment, e.g., managers and salesmen. For a blue collar worker employed forty hours per week the predicted probability of switching was close to zero. Controlling for a large number of economic and demographic variables, the self-employed were significantly more likely to continue to work, partly by reducing their workweek to under 35 hours. Other significant predictors of continuing to work are good health, years of schooling, white collar occupation, no expectation of a private pension, and a workweek longer than fifty hours. Age is also important, especially at the eligibility ages set by social security.
\end{abstract}

Victor R. Fuchs

National Bureau of Economic Research 204 Junipero Serra Boulevard

Stanford, California 94305

$415 / 326-7160$ 


\title{
SELF-EMPLOYMENT AND LABOR FORCE PARTICIPATION OF OLDER MALES
}

\author{
Victor R. Fuchs
}

\section{Introduction}

\section{Background}

The labor market behavior of older workers is receiving increasing attention from social scientists at the same time that policies affecting such behavior are becoming important subjects of public debate. Empirical economic research has concentrated primarily on explaining labor supply-especially the retirement decision--with ill health, social security payments, private pensions, assets, income, wage rates, taxes, and the business cycle the main variables of analysis. $1 /$ some economic research, primarily theoretical, has attempted to explain other phenomena such as seniority rules, rigidity of wages at older ages, and mandatory retirement. $\underline{2}$ Recent policy discussions have focused on the desirability of raising or eliminating mandatory retirement ages, raising the social security retirement age, and reducing or eliminating the implicit tax on earnings of those eligible for social security retirement benefits.

The principal reason for the increase in interest in older workers is the realization that current retirement patterns, longer life expectancy, and a slowing-down in the growth of the non-aged labor force will eventually necessitate either large increases in taxes or large decreases in benefits to retired workers. Short of large-scale immigration there is not much that can be done to change the size of the non-aged labor force for at least the next 20 years, and no one is advocating 
shorter life expectancy. Thus, there is growing support for efforts to
reverse the trend toward earlier retirement.
$\therefore$ According to Gordon and Blinder (1980) there are five basic classes of reasons why older people retire from the labor force. They are: poor health, age-related declines in wages for reasons other than health, incentives created by the social security retirement system, incentives created by private pensions, and age-related shifts in preferences toward leisure. In a recent study, based on cross-section analysis of Retirement History Study data, they find strong effects from wages and private pensions, a "substantial, though not overwhelming" effect of ill health, some support for a shift in preferences, but an insignificant effect from social security. Boskin (1977), on the other hand, has questioned the significance of health and has emphasized the importance of social security retirement benefits, as have Pellechio (1979) and several other investigators.

Most of the published studies have concentrated on wage-andsalary workers alone; the self-employed are typically excluded. An important exception is Quinn $(1980 a, b)$, who has looked specifically at the self-employed, and who has called attention to "partial retirement." He has speculated that some wage-and-salary workers switch to self-employment toward the end of the life cycle as an alternative to withdrawal from the labor force. He assumes that there is much more flexibility in hours and wages among the self-employed and that the change in class of work is a form of partial retirement.

The increased importance of self-employment at older ages is a well established feature of the U.S. labor market. For instance, in 
cross-sectional data the proportion self-employed among white urban male workers rises from about 15 percent in the late fifties to more than 25 percent by the late sixties. (See Table 1, column 1.) Given a long-term trend away from self-employment, $\stackrel{3 /}{ }$ this increase may be partly a cohort effect. However, in longitudinal data from the Retirement History Study (columns 2 through 7 of Table 1), life-cycle effects within cohorts are also very pronounced. Indeed, for every birth cohort except 1907, the within cohort change is slightly larger than that revealed in the cross-section, possibly for cyclical reasons or as an artifact of the RHS sample.

The observed increase in the importance of self-employment over the life cycle can result from class-of-worker differences in continuation at work or from shifts by wage-and-salary workers into self-employment, or both. Table 2 shows that both phenomena were present during the period under study. In the 1969-71 and 1971-73 transitions approximately four to five percent of wage-and-salary workers switched to self-employment; within this eight-year segment of the life-cycle the probability of switching does not vary systematically with age. Aclass-of-worker differential in the probability of continuing to work is also readily apparent. This probability was higher for the selfemployed than for wage and salary workers at every age in both transitions. The differential in the probability loes vary with age, rising from a very small difference at 58 and 59 to a very large one in the middle sixties.

This paper focuses on both the switch to self-employment and the class-of-worker differential in the probability of continuing to work. First, the increase in the relative importance of seli-employment at each age is decomposed into its two sources. Second, the results of multiple regressions of the probability of switching are presented. The principal 
Table 1. Self-employed as percent of total employed, by age, white urban males, 1969, 1970, 1971, 1973.

\begin{tabular}{|c|c|c|c|c|c|c|c|}
\hline \multirow[b]{2}{*}{ Age } & \multirow{2}{*}{$\begin{array}{l}\text { Cross-section } \\
1970 \text { a }\end{array}$} & \multicolumn{6}{|c|}{ Birth cohort- } \\
\hline & & 1911 & 1910 & 1909 & 1908 & 1907 & 1906 \\
\hline 55 & 14.9 & & & & & & \\
\hline 56 & 14.6 & & & & & & \\
\hline 57 & 15.2 & & & & & & \\
\hline 58 & 15.1 & 13.4 & & & & & \\
\hline 59 & 14.6 & & 13.4 & & & & \\
\hline 60 & 14.8 & 16.5 & & 13.5 & & & \\
\hline 61 & 13.8 & & 15.6 & & 13.9 & & \\
\hline 62 & 16.6 & 18.7 & & 15.6 & & 16.2 & \\
\hline 63 & 15.9 & & 21.7 & & 17.6 & & 15.4 \\
\hline 64 & 17.5 & & & 19.9 & & 20.0 & \\
\hline 65 & 21.5 & & & & 25.4 & & 24.2 \\
\hline 66 & 23.6 & & & & & 21.3 & \\
\hline 67 & 25.6 & & & & & & 34.2 \\
\hline 68 & 26.2 & & & & & & \\
\hline 69 & 26.5 & & & & & & \\
\hline
\end{tabular}

a / $1 / 100$ sample, 1970 Census of Population.

b/Retirement History Study, 1969, 1971, 1973. 
Table 2. Probabilities of switching to self-employment and of continuing to work, 1969-71 and 1971-73, white urban males, by age (standard error in parentheses).

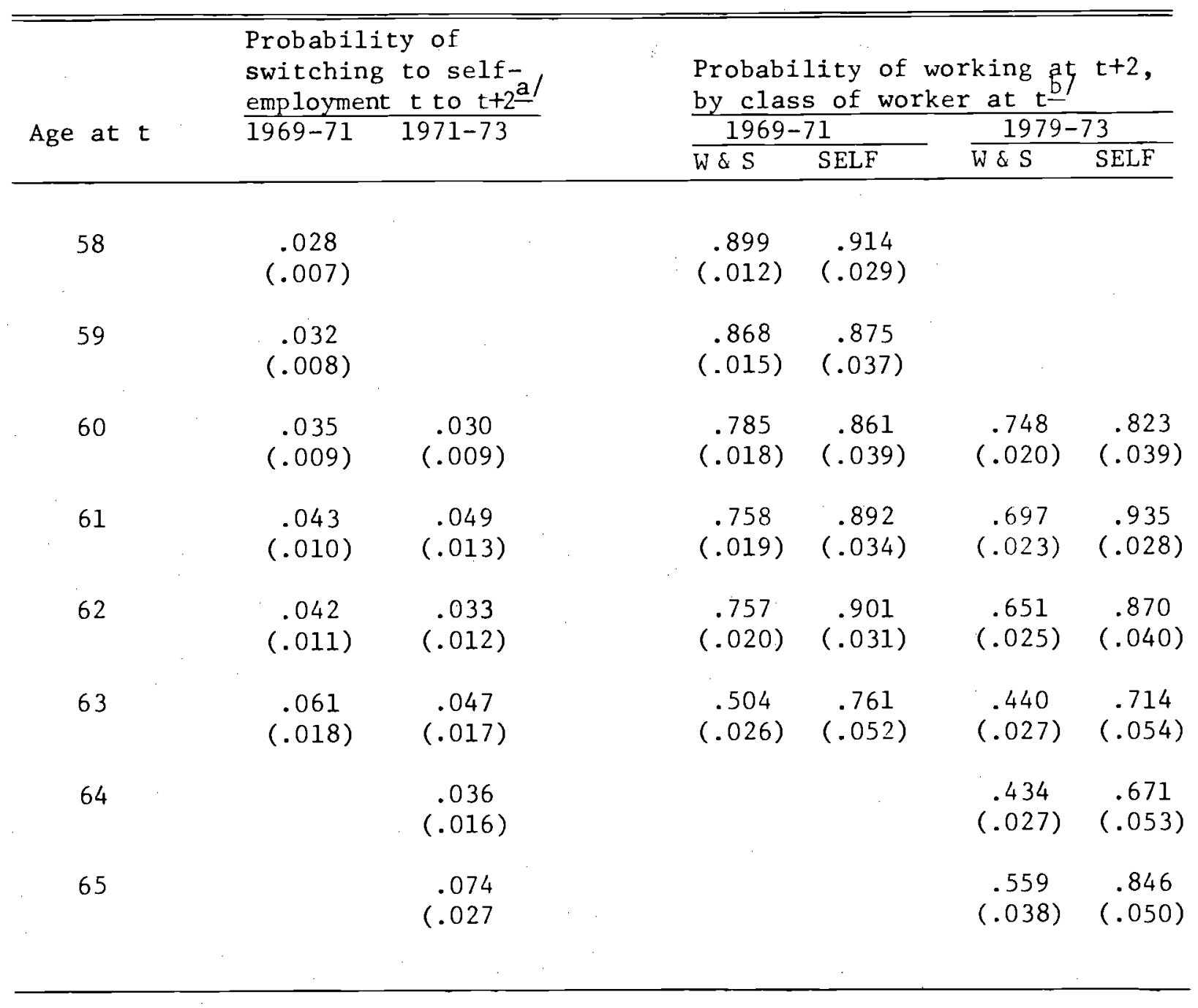

a/ Conditional on working at $t$ and $t+2$.

b/Conditional on working at $t$ and not lost from sample $t+2$.

Source: Retirement History Study. 
empirical section of the paper provides new estimates of the impact of class of worker, ill health, wages, social security, private pensions, mandatory retirement, and other variables on the labor force participation of older males. The analysis is longitudinal and focuses on the probability of being at work at $t+2$ and $t+4$ years conditional on working at year $t$. The final set of regressions tests the hypothesis that the higher propensity of the self-employed to continue to work at older ages is related to their ability to reduce their work week to less than 35 hours.

The Data

The data used in this paper come from the Retirement History Study, ${ }^{4}$ which began in 1969 when the subjects were ages 58 through 63 . Responses to interviews conducted in 1971 and 1973, as well as 1969, are included. I have restricted the analysis to white urban males in order to eliminate complications introduced by sex and race differences in behavior, and to avoid definitional problems concerning the labor force participation of older farmers. Class of worker was determined by the response to the question "Are you (a) an employee of a private company, (b) a government employee, (c) self-employed, (d) working without pay?" Those who responded (a) or (b) were classified as "wage-and-salary." The very small number who responded (d) were treated as not working. In 1969 there were approximately 3500 white urban males in the sample who were at work and who were retained in the sample in $1971.5 /$ Approximately 2500 were working in 1971 and retained in the sample in 1973. During each transition approximately 12 percent of the men who were working 
at time $t$ were lost from the sample by $t+2$. Individuals were lost from the sample through death, institutionalization, refusal to respond to subsequent interviews, or unreported change in location. In general, men lost from the sample did not have significantly different characteristics from those retained. For men working at time $t$, the only statistically significant predictor of being lost from the sample at $t+2$ is the presence of a health-related work limitation. $\frac{6}{}$ The analysis is restricted to men who were working in the initial year of each transition in order to focus on subsequent changes in status with a full set of observations for all variables .

Sources of Increase in Self-employment

One of the advantages of the longitudinal data is the opportunity they afford for decomposing the life-cycle increase in the relative importance of self-employment into the share attributable to a class of worker differential in continuing to work, and the share attributable to a net shift into self-employment. 
Let

$$
\begin{aligned}
& S_{t}=\text { number of self-employed workers in initial year; } \\
& \mathrm{T}_{t}=\text { total number of workers in initial year; } \\
& \mathrm{S}_{\mathrm{t}+2} \text { and } \mathrm{T}_{\mathrm{t}+2}=\text { the same in terminal year; } \stackrel{?}{ } \\
& \hat{S}_{t+2}=\frac{S_{t}}{T_{t}} T_{t+2}=\text { "expected" number of self-employed if } \\
& \text { the relative importance of self-employment } \\
& \text { remained constant; } \\
& \mathrm{X}=\text { number of wage and salary workers in initial year } \\
& \text { who were self-employed in terminal year; } \\
& \mathrm{Y}=\text { number of self-employed workers in initial year who } \\
& \text { were wage and salary in terminal year; } \\
& C=\frac{S_{t+2}}{T_{t+2}}-\frac{S_{t}}{T_{t}}=\begin{array}{l}
\text { change in relative importance of } \\
\text { self-employment; }
\end{array} \\
& P=\frac{X-Y}{S_{t+2}-\hat{S}_{t+2}}(100)=\begin{array}{l}
\text { percent of } c \text { attributable to net } \\
\text { switching of class of worker. }
\end{array}
\end{aligned}
$$

This decomposition, shown in Table 3 , reveals that the source of the increase in self-employment varies considerably with age. For those men who were 58 or 59 in 1969 , al1 of the increase is attributable to switching from wage and salary to self-employed status. At age 60 (cohorts 1909 in 1969, and 1911 in 1971), shifts in class of worker and differential continuity of work are about equal in importance. Above age 60 differential work patterns become more important than shifting, accounting for at least 60 percent and sometimes all of the increase in 


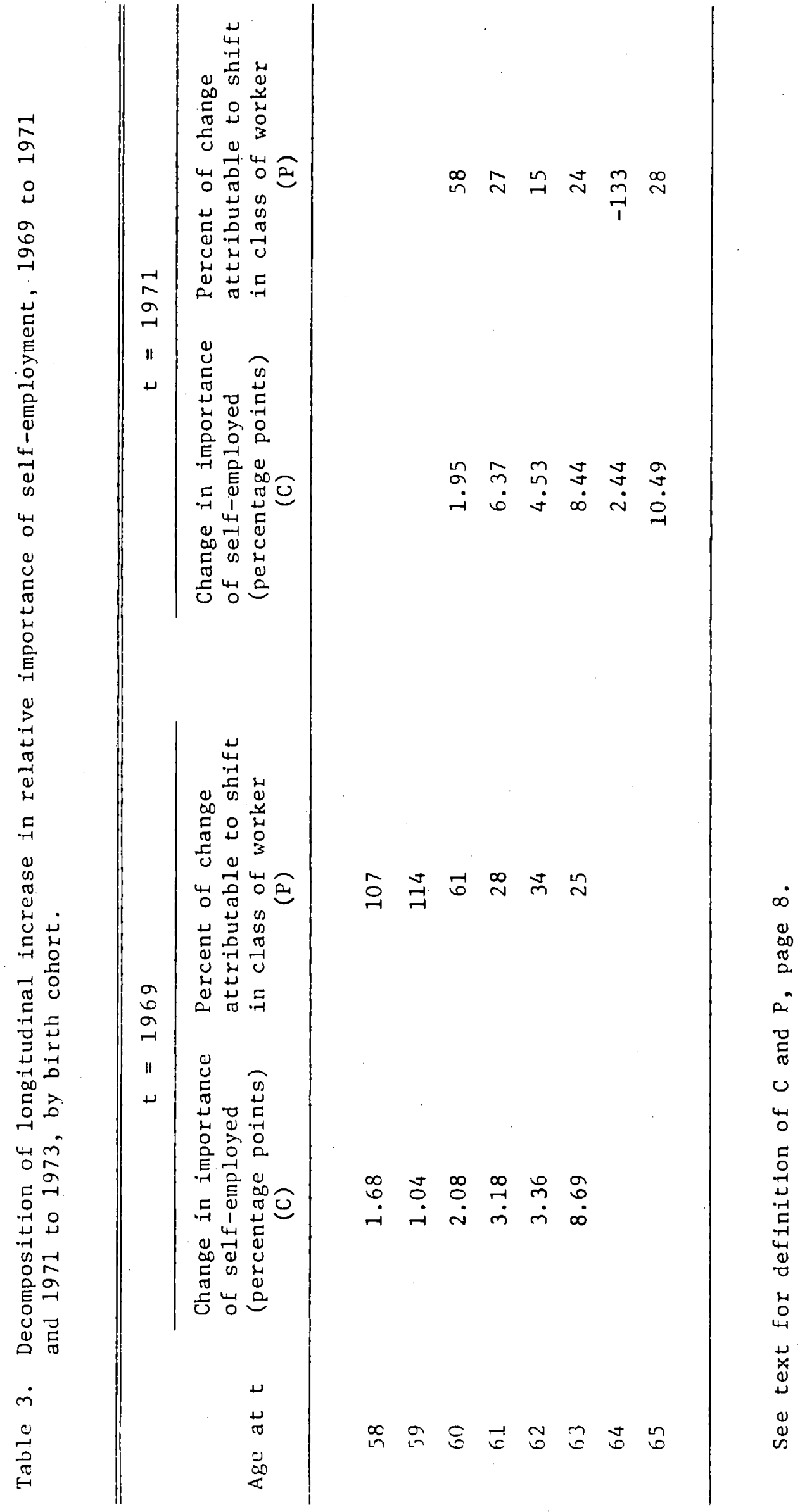


the relative importance of self-employment. For the sample as a whole, it appears that both switching and differential continuity are important. The balance of the paper, therefore, is devoted to the questions: "Who switches?" and "Who continues to work?"

\section{$\underline{\text { Regression Analysis }}$}

Model and Variables

In order to explore systematically whether those older men who continue working differ in predictable ways from those who stop, and whether those wage and salary workers who switch to self-employment late in life are different from those who do not, a series of maximum likelihood logit regressions were run based on the transitions from 1969 to 1971 and from 1971 to 1973 (and sometimes 1969 to 1973). Because results for each transition were similar, only the pooled results are reported in the paper. The independent variables used in the regressions are defined in Table 4 and mean values are shown in Table 5. YRSPRSE, which measures previous experience in self-employment, was obtained from social security records that were matched to each individual. A second group of variables describes the job at time $t$. There are four weekly hours dumnies, four hourly wage dummies, and four dummy variables for occupation. Personal characteristics are covered by three health status dummies, a continucus variable measuring years of schooling, and a separate dumy variable for each single year of age. There are four dummy variables describing private pension expectations and mandatory retirement status, and three dummy variables for expected 
Table 4. Definitions of independent variables.

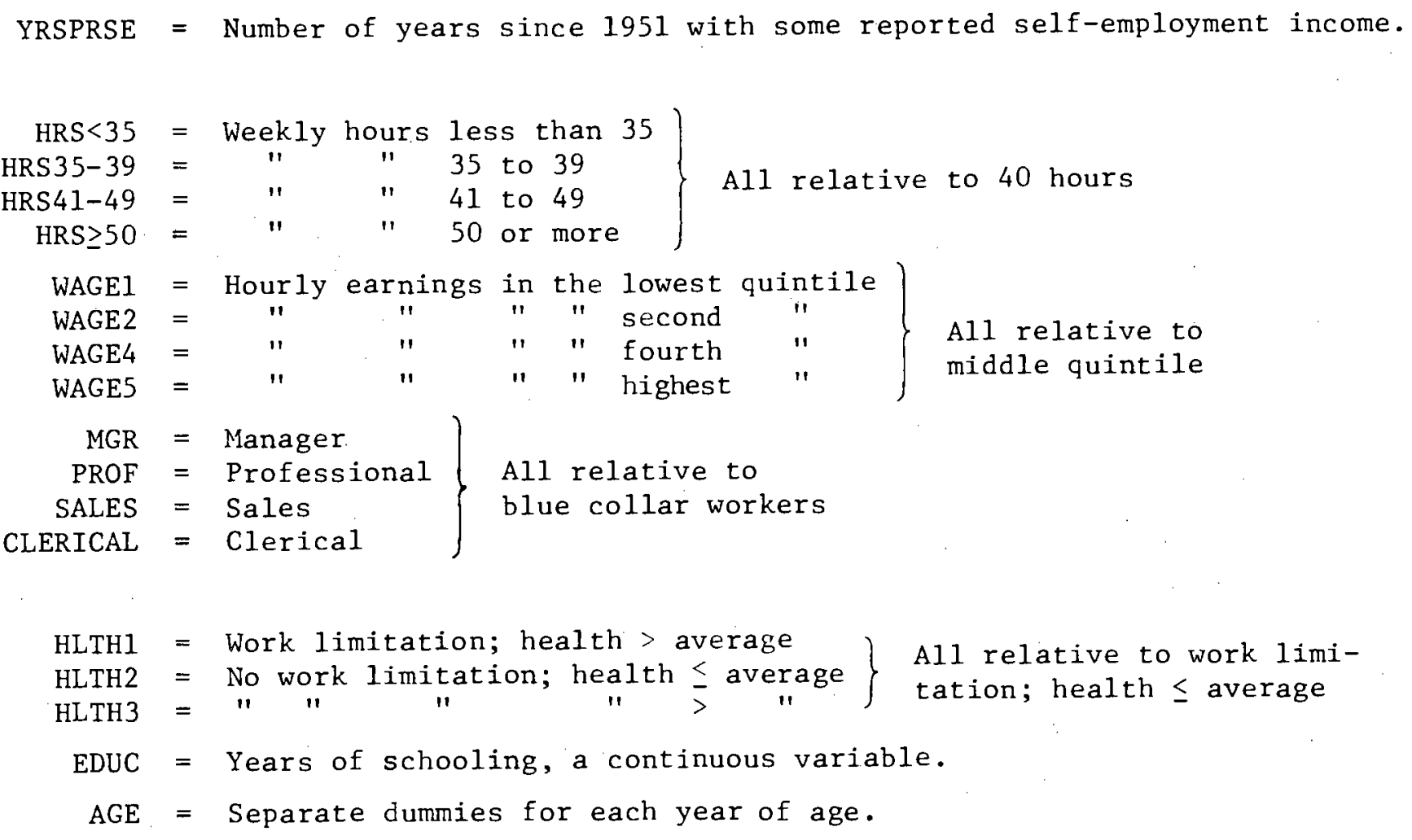

$\mathrm{PN} / \mathrm{NOR}=$ Eligible for pension, no mandatory retirement NOPN/R>t+2 = Not eligible for pension, mandatory retirement after year $t+2$

$\mathrm{PN} / \mathrm{R}>\mathrm{t}+2=$ Eligible for pension, mandatory retirement after year $t+2$

$R \leq t+2=$ Mandatory retirement by year $t+2$ (regardless of pension status)

All relative to no pension and no mandatory retirement

a/ A full description of the algorithms used to construct the variables is available upon request. 
Table 5. Mean values of dependent and independent variables by class of worker; sample limited to those working at $t$ and still sampled at $t+2$.

\begin{tabular}{|c|c|c|c|c|c|c|}
\hline & \multicolumn{3}{|c|}{$t=1969$} & \multicolumn{3}{|c|}{$t=1971$} \\
\hline & $W \& S$ & SELF & ALL & $\mathrm{W} \& \mathrm{~S}$ & SELF & ALL \\
\hline \multicolumn{7}{|l|}{ Dependent } \\
\hline Prob. of switching to SELF at $t+2$ a/ & .04 & NA & $\mathrm{NA}$ & .04 & NA & NA \\
\hline Probability of working at $t+2$ & .78 & .87 & .79 & .61 & .81 & .64 \\
\hline \multicolumn{7}{|l|}{ Independent } \\
\hline YRSPRSE & .99 & 11.56 & 2.47 & 1.13 & 12.08 & 3.03 \\
\hline HRS $<35$ & .04 & .15 & .06 & .06 & .17 & .08 \\
\hline HRS $35-39$ & .07 & .06 & .07 & .08 & .04 & .07 \\
\hline HRS $41-49$ & .16 & .12 & .16 & .14 & .12 & .14 \\
\hline $\mathrm{HRS} \geq 50$ & .16 & .50 & .21 & .12 & .44 & .18 \\
\hline WAGE1 & .18 & .33 & .20 & .17 & .27 & .19 \\
\hline WAGE2 & .20 & .15 & .19 & .20 & .15 & .19 \\
\hline WAGE4 & .21 & .10 & .20 & .21 & .10 & .19 \\
\hline WAGE 5 & .18 & .21 & .19 & .17 & .27 & .19 \\
\hline MGR & .16 & .44 & .20 & .15 & .47 & .21 \\
\hline PROF & .11 & .16 & .12 & .10 & .17 & .12 \\
\hline SALES & .06 & .07 & .06 & .06 & .08 & .06 \\
\hline CLER & .08 & .01 & .07 & .08 & .01 & .07 \\
\hline HLTHI & .04 & .05 & .04 & .04 & .05 & .04 \\
\hline HLTH 2 & .42 & .31 & .41 & .46 & .38 & .44 \\
\hline HLTH 3 & .38 & .41 & .39 & .34 & .35 & .34 \\
\hline EDUC & 10.62 & 11.49 & 10.75 & 10.68 & 11.79 & 10.88 \\
\hline Cohort 1906 & .12 & .14 & .13 & .08 & .12 & .09 \\
\hline 1907 & .16 & .18 & .16 & .15 & .18 & .16 \\
\hline 1908 & .17 & .17 & .17 & .16 & .16 & .16 \\
\hline 1910 & .17 & .16 & .17 & .19 & .17 & .19 \\
\hline 1911 & .20 & .19 & .20 & .23 & .22 & .23 \\
\hline SS55-99 & .15 & .23 & .16 & .16 & .21 & .16 \\
\hline $100-124$ & .10 & .20 & .11 & .11 & .15 & .11 \\
\hline$\geq 150$ & .37 & .18 & .34 & .33 & .24 & .31 \\
\hline $\mathrm{PN} / \mathrm{NOR}$ & .34 & .17 & .31 & .29 & .17 & .27 \\
\hline NOPN/R $t+2$ & .04 & .00 & .03 & .03 & .00 & .02 \\
\hline $\mathrm{PN} / \mathrm{R} \mathrm{t}+2$ & .31 & .01 & .26 & .32 & .01 & .27 \\
\hline$R \leq t+2$ & .03 & .00 & .03 & .09 & .00 & .08 \\
\hline$------\infty-\infty-$ & $-\quad-$ & -- & -- & --- & -- & -- \\
\hline Number of observations & 3001 & 493 & 3494 & 2115 & 443 & 2558 \\
\hline
\end{tabular}

a/ Conditional on working at $t+2$.

$\mathrm{NA}=$ not applicable. 
social security income calculated from matched social security records using an algorithm developed by Ken Cone at the NBER in Palo Alto.

Who Switches to Self-employment?

Table 6 reports the results of a regression designed to answer the question "Who switches to self-employment?" The sample is restricted to the men who were working as wage-and-salary workers in the initial year (1969 or 1971) and who were also working in the terminal year (1971 or 1973) 1973). $9 /$ The dependent variable is dichotomous, taking a value of 1 if the subject switched to self-employment, and 0 if he continued as a wage-and-salary worker. The marginal effect of each independent variable, evaluated at mean probability, is shown after the regression coefficient and its standard error.

We see that previous experience with self-employment, occupation, and weekly hours at current job are all significant predictors of the probability of a wage-and-salary worker switching to self-employment. Also, wage-and-salary workers who are subject to mandatory retirement beyond $t+2$ or who expect a private pension are less likely to switch. On the other hand, expectations about the amount of social security income, health status, education, age, and wages are not significantly related to changes from wage and salary to self-employment status. A dummy variable that compares the probability of switching in 1971-73 vs. 1969-71 is also insignificant.

It is quite clear that the men who switched to self-employment are primarily those who have had previous experience in self-employment 
Table 6. Maximum likelihood logit regression results: probability of switching from wage-and-salary to self-employment.

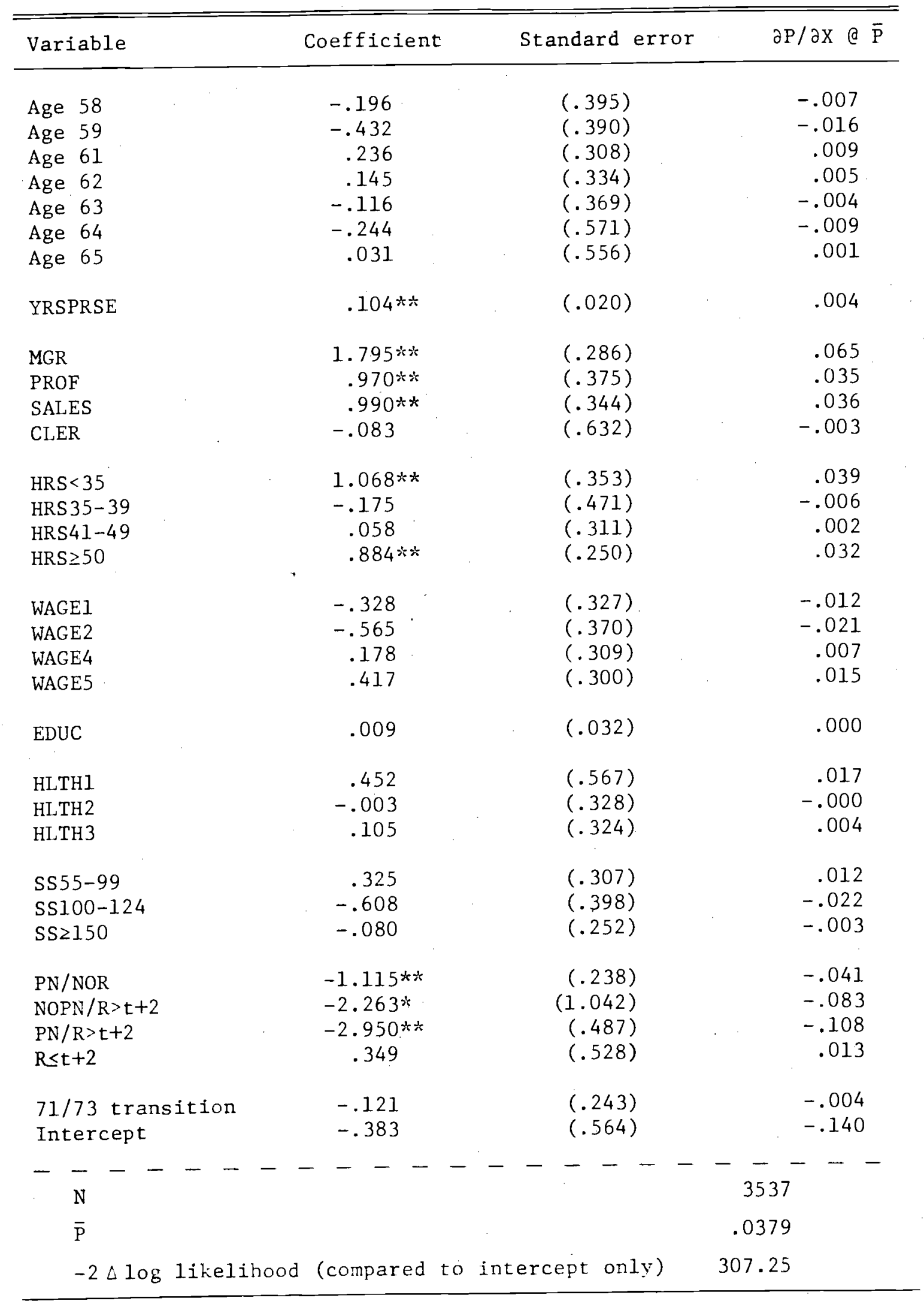

\footnotetext{
*Significant at $\mathrm{p}=.05$.

${ }^{*}$ Significant at $p=.01$.
} 
or who are in wage-and-salary jobs that are similar in many respects to self-employment. Managers, professionals, and salesmen, for instance, frequently have a good deal of discretion as to how they spend their time, and their compensation is frequently closely tied to their performance. Also, the very short $(<35)$ or very long ( $\geq 50)$ work weeks reported by the switchers while they were in wage-and-salary employment are characteristic of the self-employed. The contrasts among wage-and-salary workers in the probability of switching is quite striking. Although the mean probability of changing to self-employment is .04 , the predicted probability for a blue collar worker with a 40-hour per week job, eligible for a pension, and no previous self-employment experience, is only $.003 .9 /$ On the other hand, the predicted probability for a manager with some self-employment income in any ten years since 1951, an unusually short or long work-week, not eligible for a private pension, and not subject to mandatory retirement is .52 .

Who Continues to Work?

The regression results presented in Table 7 provide some intriguing answers to the question "Who continues to work:" This formulation is used rather than "Who retires?" for two reasons. First, it is possible to determine with considerable accuracy whether a man is working or not at a given time, whereas the concept of "retirement" is ambiguous. For instance, in these data some men who state that they are "retired" are also working. Second, other investigators are using these data to study "retirement"; the results reported here provide some insight into the importance of the particular formation of the question. 
Table 7. Maximum likelihood logit regression results: probability of continuing to work.

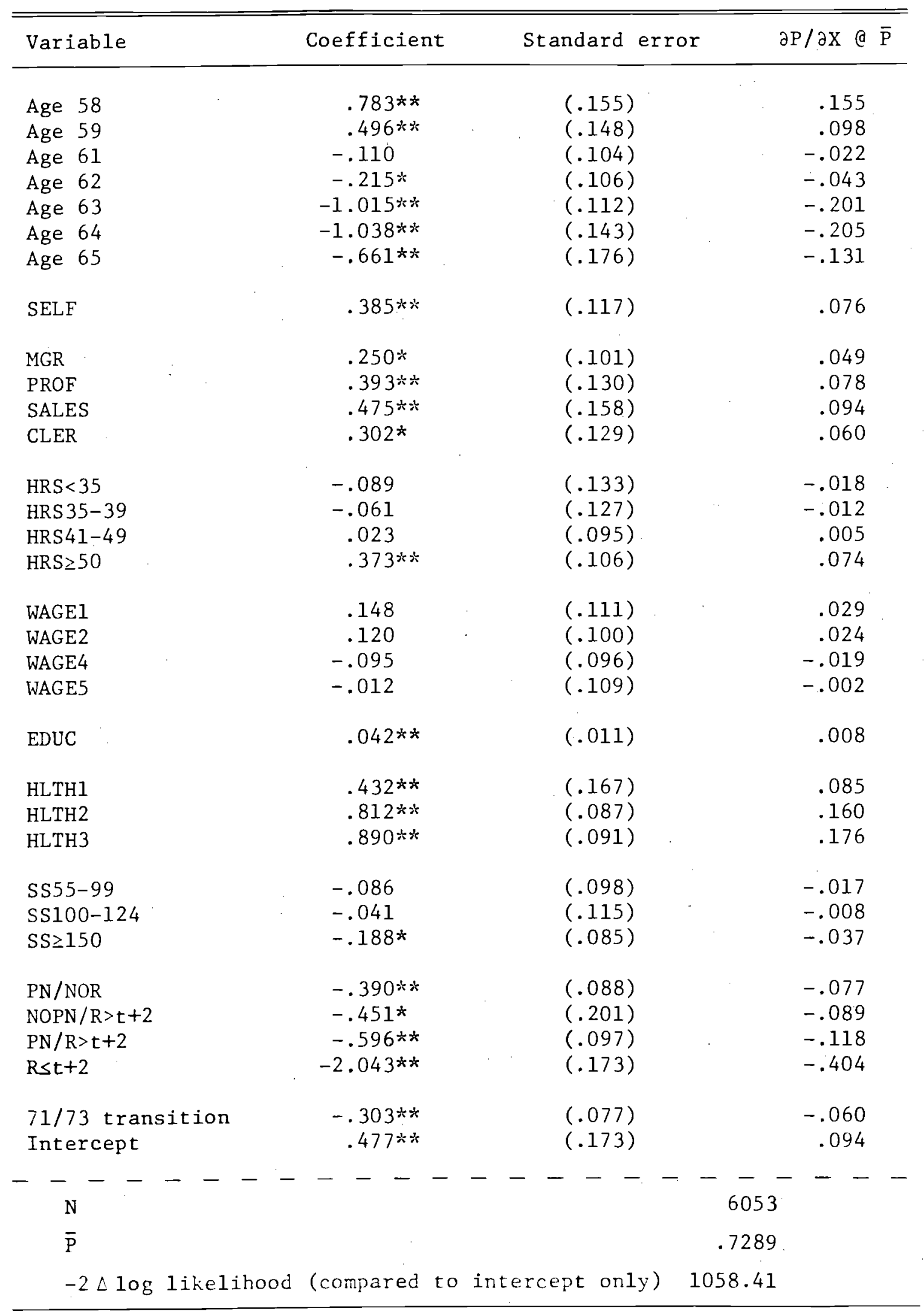

${ }^{\star}$ Significant at $\mathrm{p}=.05$.

${ }^{* *}$ Significant at $p=.01$. 
The analysis is restricted to men working in the initial year who were sampled in the terminal year. The dependent variable is dichotomous, taking a value of 1 if the man was also working in the terminal year, and 0 if he was not. The independent variables are the same as in the switching regression, except that a dummy variable for self-employment is substituted for PRVSE. The results are discussed by groups of variables.

Class of worker and age. The regression results presented in Table 7 confirm the inferences drawn from Tables 2 and 3 that the selfemployed are more likely to continue working than are wage-and-salary workers. Evaluated at mean probability, and controlling for other variables, the class of worker differential is almost 8 percentage points. In regressions based on the transition from 1969 to 1973 (not shown here) it is possible to compare the probability of continuing to work of men who had been self-employed in 1969 with that of men who switched to self-employment in 1971. The coefficients are the same to two decimal places and the coefficients for the other variables are very similar to those shown in Table 7.

This table also shows that age is significant, but there are substantial discontinuities in the effect of age, probably because of the structure of the social security law. If withdrawal from work were determined primarily by biological aging rather than institutionally imposed incentives and constraints, the age coefficients in Table 7 would tend to change at a smooth rate. They do not. Instead, we observe a significantly larger decrease for those men who reach 65 during the transition period (i.e., those who are age 63 or 64 at $t$ ), the "normal" age for retirement under social security and many private pension 
plans. We also observe a discontinuity for men reaching 62 (age 60 at $t$ ), the eligibility age for "early" retirement under social security. This can be seen by the large positive coefficient for age 59, indicating that the change from 59 to 60 is almost twice as large as the change from 58 to 59. There are also some significant interactions between class of worker and age which will be discussed after the principal results for the other variables are presented.

Health status, pensions, mandatory retirement, and social security. Health status is a remarkably strong predictor of the probability of working. This result has been found before in several cross-section studies, but its validity has been questioned because of the possibility that respondents offer "poor health" as a rationalization for not working. The findings in this study are less subject to that criticism because all the men are working when their self-evaluation of health status is ascertained. Even in the 1969-73 regression (not shown), when health status at time $t$ is used to predict work status four years later (and the sample is restricted to men at work in 1969 and 1971 and still in the sample in 1973), the health variables do very well. Men who report no health-related work limitation, but are only in average or worse-thanaverage health, show a marginal effect of .088 (compared to those with a work limitation and average or worse-than-average health), while men with no work limitation and above-average health show a differential probability of .141 . The results of tests of possible interactions between health status and other variables are discussed below.

Table 7 also shows the strong effect of mandatory retirement within the transition period $(R \leqq t+2)$. Eligibility for a private pension and/or 
mandatory retirement beyond $t+2$ also decreases the probability of continuing to work. Expectations about social security income do not have a strong effect. The highest benefit category, however, has a negative coefficient which is statistically significant at $p<.05$.

Education, occupation, hours, and wages. The effects of jobrelated variables--hours, wages and occupation--and the education of the worker are mixed. Ceteris paribus, education and occupation are quite significant; hours and wages are not. We see that each year of schooling adds almost one percentage point to the probability of working in the terminal year. The occupation dummies show that white-collar workers are much more likely to continue working than are blue-collar workers. Most of the hours dummies are not significant, but nen who work 50 hours per week or more at time $t$ have a significantly higher probability of being at work at $t+2$. This finding is contrary to the results of Burkhauser and Turner (based on men at younger ages); they suggested that workers substitute between longer hours and longer labor force participation. Perhaps there are other unmeasured characteristics possessed by some men who "like" to work. The wage variables are not statistically significant, which is contrary to the cross-section results of Gordon and Blinder, who estimated wages and included men not at work.

The 1971-73 dummy variable. In contrast to the insignificant transition dummy in the switching regression, the probability of continuing to work 1971-73 was significantly lower than in 196:-71. This is the opposite of what would be expected for cyclical reasons. The white adult male unemployment rate actually fell from 4.0 percert in 1971 to 2.9 percent 
in 1973 after rising from 1.9 percent in 1969. The sharper decline in work during the 1971-73 transition is probably the result of a substantial increase in social security benefits during that period.

Interactions between variables. Several sets of regressions were run to test for possible interactions among age, health status, class of worker and pension status. Surprisingly few significant differences emerged. The most notable interaction is between age and class of worker (see Table 8). As previously noted (Table 2), there is little difference between selfemployed and wage-and-salary workers in the probability of continuing to work for the younger men in the sample. At ages 61 (at $t$ ) or above, the class of worker effect is substantial. A similar interaction with age is observed for the PN/NOR variable. At the older ages in this sample eligibility for a private pension has a much larger negative effect on the probability of continuing to work than at the younger ages.

There have been a number of suggestions that the effects of poor health on labor force participation should vary, depending upon age, education, class of worker, occupation, and the like.11/ These hypotheses are not confirmed in this sample. For instance, when the sample is divided into three groups according to health status, $\underline{12 /}$ the coefficients for the other variables do not vary systematically and significantly with health status.

A simple summation of the principal findings of the working-not working regression is presented in Table 9 in the form of estimated probabilities of working for three hypothetical men: Mr. A, assumed to be a professional, self-employed, 17 years of schooling, hours $\geq 50$, no work limitation and health above average, no pension or mandatory retirement; Mr. B, clerical, 
Table 8. Maximum likelihood logit regression results: probability of continuing to work, by age (standard errors in parentheses).

\begin{tabular}{|c|c|c|c|}
\hline \multirow{2}{*}{\multicolumn{2}{|c|}{ Age at $t$}} & \multicolumn{2}{|c|}{ Variable } \\
\hline & & SELF & PN/NOR \\
\hline 58 and 5 & 59 & $-.047(.326)$ & $-.185(.259)$ \\
\hline 60 & & $-.092(.274)$ & $-.146(.208)$ \\
\hline 61 & & $.790(.328)$ & $-.381 \quad(.212)$ \\
\hline 62 & & $.800(.312)$ & $-.355(.219)$ \\
\hline 63 & & $.391(.253)$ & $-.598(.201)$ \\
\hline 64 and $\epsilon$ & 65 & $.545(.276)$ & $-.635(.234)$ \\
\hline
\end{tabular}

a/ Controlling for all other variables. 
Table 9. Predicted probability - / working at $t+2$, by age, three hypothetical white urban males.

\begin{tabular}{ccccc}
\hline \hline & \multicolumn{4}{c}{ Pooled $1969-71+1971-73$} \\
\cline { 2 - 5 } Age at $t$. & Full sample & Mr. A & Mr. B & Mr. C \\
\hline 58 or 59 & .89 & .99 & .97 & .72 \\
60 & .78 & .91 & .86 & .61 \\
61 & .76 & .97 & .80 & .53 \\
62 & .74 & .94 & .72 & .40 \\
63 & .52 & .90 & .57 & .12 \\
64 or 65 & .53 & .89 & .60 & .03 \\
\hline
\end{tabular}

Mr. A = Professional, self-employed, 17 years of schooling, hours $\geq 50$, no work limitation and health > average, no pension or mandatory retirement. $\underline{b}$ /

Mr. $B=$ Clerical, wage and salary, 13 years of schooling, hours $=40$, no work limitation and heglth $\leq$ average, pension but no mandatory retirement.

Mr. $\mathrm{C}=$ Blue collar, wage and salary, 10 years of schooling, hours $=40$, work limitation and health $\leq$ average, pension and mandatory retirement at age 65 . b

a/ Estimated from maximum likelihood logit regressions by single year of age.

b/Assuming omitted class values for wages and social security benefits. 
wage-and-salary, 13 years of schooling, hours $=40$, no work limitation and health $\leq$ average, pension but no mandatory retirement; and $\mathrm{Mr} . \mathrm{C}$, blue collar, wage-and-salary, 10 years of schooling, hours $=40$, work limitation and health $\leq$ average, pension and mandatory retirement at age 65 . For all three men the omitted class values are assumed for wages and social security benefits.

We observe large variation in the probability of continuing to work among these men, especially at older ages. For Mr. A the probability of continuing to work is close to unity at all ages through $t=65$. Mr. B has a high probability at the younger ages, but it declines with age, primarily because of the interaction between age and the class of worker and pension effects. Mr. C has a lower probability even at 58 and 59, and the probability of his continuing to work falls to virtually zero when $t=65$.

A final regression was run to determine the extent to which the class of worker differential in the probability of working is related to greater opportunities for the self-employed to work short hours. These regressions omitted men who were working fewer than 35 hours per week at $t$ and men who changed class of work, leaving 5263 observations. Three possible states at $t+2$ were specified: working $\geq 35$ hours per week, working < 35 hours per week, and not working. A polytomous logit regression was estimated by maximum likelihood. The coefficients were then used to calculate the predicted probability of being in each state for the selfemployed and wage-and-salary workers, assuming omitted class for other categorical variables and mean education (see Table 10).

This analysis suggests that differential opportunity to reduce weekly hours under 35 does contribute substantially to the class of 
Table 10. Maximum likelihood polytomous logit regression results: predicted probabilitya af work status at $t+2$ by class of worker, non-switchers working $\geq 35$ hours at $t$.

\begin{tabular}{lccc}
\hline \hline & \multicolumn{3}{c}{ Class of worker } \\
\cline { 2 - 4 } State at $\mathrm{t}+2$ & Self-employed & Wage-and-salary & $\begin{array}{c}\text { Self-employed minus } \\
\text { wage-and-salary }\end{array}$ \\
\hline & & & .034 \\
Working $\geq 35$ hours & .729 & .695 & .020 \\
Working $<35$ hours & .052 & .032 & -.055 \\
Not working & .219 & .274 & \\
\hline
\end{tabular}

a/ Assuming omitted class for other categorical independent variables and mean education. Complete regression results available upon request. 
worker differential in the probability of continuing to work. Almost 40 percent of the working differential of .055 is accounted for by a differential in the predicted probability of working under 35 hours per week. The factors that make short work weeks more viable for the selfemployed than for wage-and-salary workers need to be investigated. 
$\underline{\text { Summary }}$

This longitudinal analysis of the labor market behavior of older white urban males confirms some previous findings, contradicts others, and raises new questions for further study. The paper differs from most previous research in this subject by inclusion of the self-employed, by explicit attention to changes in class of work, and by focusing on the probability of continuing to work rather than on "retirement" per se.

The continuing to work regressions provide strong support for the role of ill health in the labor force decisions of older men. Those men at work who reported a health-related work limitation at time $t$ were (ceteris paribus) much less likely to be at work two or four years later. This is a significant result because it is much less susceptible to the criticism that "poor health" simply serves as a rationalization for not working.

Age has a strong effect on the probability of continuing to work, but there are marked discontinuities in the size of the effect which seem to be associated with eligibility for social security. The probability of working at $t+2$ drops sharply when $t$ is 63 . This corresponds with the "normal" retirement age of 65 . A smaller discontinuity is observed when $t+2$ is 62 , the eligibility age for "early" retirement.

Eligibility for a private pension has a significant negative effect on the probability of continuing to work, and this effect increases with age. Men working long hours ( $\geq 50$ ) are much more likely to continue to work. Wage rates, on the other hand, do not show a significant effect. The self-employed are much more likely to continue than are wageand-salary workers. This class of worker differential increases with age 
and seems to be about as large for those who have very recently switched to self-employment as for those who have been in the class for some time. A substantial portion of the class-of-worker differential in continuing to work is accounted for by self-employed who reduce their work week from more than to less than 35 hours.

The probability of switching regressions reveals that men who change to self-employment late in life are primarily those who have had previous experience in self-employment or who are in wage-and-salary occupations such as managers and salesmen that have many characteristics similar to self-employment. For instance, men who switch tended to have either very short or very long work weeks even when they were in wage-and-salary jobs. The probability of a blue-collar worker with a 40-hour-per-week job switching to self-employment is extremely small in either of the two-year transitions. With respect to the five possible explanations for labor force withdrawal identified in the introduction to this paper, I conclude that the age of eligibility for social security and poor health are the most important, private pensions are of some importance, while biologic ageing and wage effects are of lesser significance.

This paper provides answers to some questions about labor market behavior, but the results also raise some new questions. Why do the self-employed continue to work when apparently comparable wage-and-salary workers stop? Why do they find it easier or more attractive to reduce their weekly hours below 35 than do wage and salary workers? Why do men who are working long hours each week have a higher probability of continuing to work than do those with a normal work week? Why is there (ceteris paribus) a large white collar-blue collar differential and an education differential 
in the probability of continuing to work? Apparently there are factors influencing the labor market behavior of older men that are not captured by the age, health, wage, pension, and social security variables discussed by Gordon and Blinder and included in this study. Do self-employment, education, white collar, and long hours serve as proxies for the utility or disutility associated with work? Do these variables identify men who many years ago made life-cycle plans that included higher participation rates at older ages? Research that helps to clarify the role of these variables would contribute a great deal to overall understanding of the labor market behavior of older men. 
FOOTNOTES

1. See, for instance, Boskin (1977), Boskin and Hurd (1978), Burkhauser (1979), Gordon and Blinder (1980), Pellechio (1979), and Quinn (1977).

2. See Carmichael (1980) and Lazear (1979).

3. The number of non-agricultural self-employed declined from 6.0 million in 1950 to 5.2 million in 1970.

4. See Irelan (1972).

5. Men who stated they were "looking for work" were included in the "not working." Fewer than one-third of those "looking" in 1969 were working in 1971, and the same is true for the 1971 to 1973 transition. Of those not working in 1969 , eight percent were working in 1971; the comparable figure for $1971-73$ is two percent.

6. In these data, self-evaluation of health status is a good predictor of mortality. See Taubman and Rosen (1980).

7. Counting only those who were also working in the initial year.

8. A small number of workers who were classified as wage-andsalary workers in year $t$ but who reported only self-employment income in t-1 were excluded because of the probability that they were misclassified in year $t$. When they were included in the switching regressions with a dumny variable to identify their status, this variable had a very large positive coefficient, the coefficient for YRSPSE was increased, and the other coefficients were virtually unchanged.

9. Assuming omitted class for the other categorical variables and mean education. 
10. See Burkhauser and Turner (1978).

11. See, for instance, Quinn (1977), who reports significant interactions between health status and financial variables in cross-section analysis.

12. (1) No work limitation, and health above average; (2) no work limitation, health equal or below average; and (3) work limitation. 


\section{REFERENCES}

Boskin, Michael J. (1977). "Social Security and Retirement Decisions," Economic Inquiry 15, 1-25.

Boskin, Michael J., and Michael D. Hurd (1978). "The Effect of Social Security on Early Retirement," Journal of Public Economics 10, $361-377$.

Burkhauser, Richard V. (1979). "The Pension Acceptance Decision of Older Workers," Journal of Human Resources XIV, 63-75.

Burkhauser, Richard V., and John A. Turner (1978). "A Time-Series Analysis on Social Security and Its Effect on the Market Work of Men at Younger Ages," Journal of Political Economy 86, 701-715.

Carmichael, Lorne (1980). "Seniority Rules for Layoffs," Ph.D. dissertation, Stanford University.

Gordon, Roger H., and Alan S. Blinder (1980). "Market Wages, Reservation Wages, and Retirement," NBER Working Paper 513, July.

Irelan, L. M. (1972). "Retirement History Study: Introduction," Social Security Bulletin 55, 3-8.

Lazear, Edward P. (1979). "Why Is There Mandatory Retirement?" Journal of Political Economy 87, No. 6, 1261-1284.

Pellechio, Anthony J. (1979). "Social Security Financing and Retirement Behavior," American Economic Review 69, No. 2, 284-287.

Quinn, Joseph F. (1980a). "Labor Force Participation Patterns of 01der Self-Employed Workers," Social Security Bulletin 43, April, 17-28.

Quinn, Joseph F. (1980b). "The Extent and Correlates of Partial Retirement," in progress.

Quinn, Joseph F. (1977). "The Microeconomic Determinants of Early Retirements: A Cross-sectional View of White Married Men," Journal of Human Resources XII, 329-346.

Taubman, Paul, and Sherwin Rosen (1980). "Healthiness, Education and Marital Status," NBER Conference on Economic Aspects of Health, forthcoming. 